\title{
Análise geoespacial da oferta e dos fluxos turísticos no Nordeste brasileiro
}

\author{
Geospatial analysis of tourism supply and flows in northeastern Brazil
}

\author{
Erickson Melo de Albuquerque ${ }^{1}$ \\ Eduardo Rodrigues Viana de Lima ${ }^{2}$
}

\begin{abstract}
Palavras-chave:
\section{Resumo}

Autocorrelação espacial

Contiguidade espacial

Zonas turísticas

O turismo se consolidou no mundo como uma atividade de grande relevância, sobretudo no aspecto econômico. Pela sua característica multifacetada, incluída a sua vertente espacial, pode ser estudado de forma compartimentada ou integrando seus diversos componentes. No espaço geográfico se localizam os elementos fixos e os fluxos turísticos, que se dinamizam conforme a constituição desse espaço. Na região Nordeste do Brasil o turismo é uma das atividades que movimenta consideravelmente a economia e promove o consumo dos lugares, com apoio de infraestrutura e serviços. Entretanto, ainda é um setor concentrado nas maiores cidades da região, o que contribui para reforçar as desigualdades intrarregionais. Sendo assim, se coloca oportuna a utilização de técnicas de análise geoespacial para o estudo do turismo, objetivando identificar e discutir a distribuição espacial da oferta e dos fluxos turísticos possíveis em dois recortes geográficos: no Nordeste Brasileiro (NEB) e na Região Geográfica Imediata de Princesa Isabel (RGIPI). Para tanto, foram utilizados o sistema de informação geográfica QGIS em conjunto com a linguagem $\mathrm{R}$ para tratar os dados geográficos de população, renda per capita e empreendimentos turísticos e computar os índices espaciais de autocorrelação e contiguidade I de Moran, global e local, respectivamente. Os resultados mostraram que há independência espacial na oferta turística no NEB, que se reflete também na escala local, porém sendo possível identificar zonas turísticas. Além disso, foi identificado que as maiores probabilidades de fluxos turísticos estão entre as capitais mais populosas, de maior renda e mais desenvolvidas. Considerando os dados utilizados e os resultados obtidos, verificou-se que o geoprocessamento cumpre um papel importante no estudo do turismo, uma vez que o mesmo permitiu identificar áreas para expansão dessa atividade no interior do NEB.
\end{abstract}

\section{Keywords:}

Spatial autocorrelation Spatial contiguity

Tourist areas

\begin{abstract}
Tourism has been established as a significant activity worldwide, especially in the economic aspect. As a multifaceted phenomenon, including its spatial component, the systemic perspective allows a fragmented or integrated study of its different parts. The geographic space encompasses fixed elements and tourist flows, which are dynamic according to the constitution of the space. In Northeastern Brazil, tourism is one of the activities that considerably move the economy and promote the consumption of places with the support of infrastructure and services. However, it is still a sector concentrated in the largest cities of the region, contributing to reinforcing intraregional inequalities. Therefore, it is opportune to use geospatial analysis techniques to study tourism in order to identify and discuss the spatial distribution of tourism supply and possible tourist flows on two geographic scales: in Northeastern Brazil (NEB) and in the Immediate Geographic Region of Princesa Isabel (RGIPI). For this purpose, QGIS with R language was used to treat geographic, population, per capita income, and tourist businesses data and to calculate the spatial indices of autocorrelation and Moran's I contiguity on global and local scales, respectively. The outcomes revealed the spatial independence of tourist supply in the NEB, which is also seen on a local scale in the RGIPI. The analysis also revealed that the highest probabilities of tourist flow occur between the most populous, higher income, and more developed capitals. Therefore, geoprocessing plays a key role in the study of tourism as it materializes in geographical space and allows highlighting areas for tourism expansion in the interior of the NEB.
\end{abstract}




\section{INTRODUÇÃO}

O turismo é uma atividade humana plurissetorial responsável por uma fatia cada vez maior da economia global. É também um fenômeno espacial, pois os elementos envolvidos têm uma localização geográfica, sejam esses estáticos ou em fluxo. Trata-se do consumo de lugares, divulgado pela propaganda e apoiado por uma infraestrutura capaz de atender às necessidades dos turistas.

A região nordeste do Brasil é nacionalmente reconhecida como possuidora de muitos atrativos turísticos, sobretudo na faixa litorânea, onde se localizam as praias e se registra parte da história da região. Suas maiores cidades se estruturaram sobre essa riqueza patrimonial para impulsionar as atividades turísticas, favorecidas historicamente pela forma como se deu o processo de ocupação na região (ALVES; DANTAS, 2016) e pela atenção despendida pelo Estado brasileiro, especialmente após a década de 1980 (COSTA, 2012).

A oferta turística é exitosa quando o lugar a ser consumido possui estrutura para receber os visitantes (hospedá-los, alimentá-los, ofertá-los produtos e serviços), como acontece nas capitais e nas regiões metropolitanas nordestinas (SOUZA; SILVEIRA NETO, 2015).

Além disso, há também localidades potencialmente turísticas que não conseguem desenvolver atividades nem se integrar a municípios adjacentes onde o turismo é uma realidade. Entende-se com potencial turístico as localidades onde há patrimônio turístico não explorado, ou seja, existe a matéria prima, mas não o desenvolvimento das atividades turísticas, sobretudo no interior da região nordeste (GOMES, 2019).

Isto posto, o objetivo deste trabalho foi analisar o cenário de contiguidade espacial da oferta e dos fluxos turísticos em duas escalas geográficas: regional (Nordeste Brasileiro) e local (Região Geográfica Imediata de Princesa Isabel, no interior do estado da Paraíba).

\section{FUNDAMENTAÇÃO TEÓRICA}

O turismo é um fenômeno multifacetado que é dinamizado no e pelo espaço geográfico, relevante em diversos aspectos da vida humana, como na economia, na cultura e nas relações sociais. Sob essa perspectiva, Beni (2006) compreende o turismo como um fenômeno sistêmico, composto por vários subsistemas que interagem entre si para atingir um objetivo. Por essa visão, o turismo possui propriedades sistêmicas que podem ser medidas, manipuladas e controladas, como desempenho, gestão e recursos.

Além disso, o espaço geográfico é entendido no turismo como um objeto de consumo, pois é onde acontecem as atividades que direta ou indiretamente o modificam, inserindo ou removendo funções e significados por meio de interações entre sociedade e natureza, que podem ser investigadas por análises geográficas que se interessam pela produção desse espaço, decorrente das relações que se desenvolvem localmente (MUNIZ; CASTRO, 2018).

$\mathrm{Na}$ dinâmica que o turismo imprime sobre o espaço está a exploração de potencialidades, que é aumentada ou diminuída à medida que se provoca uma demanda social, e se constitui como um processo mutável de produção desse espaço no tempo, que pode atender a essa demanda ou nada oferecer - e esvaziar a atratividade local. Portanto, são os elementos constituintes do espaço geográfico que determinam a sua produção, promovendo a criação de espaços turísticos de acordo com as condições materiais existentes (MUNIZ; CASTRO, 2018).

Assim, o desenvolvimento do turismo como atividade sócio-econômica-espacial-ambiental é almejada por grupos e indivíduos sociais diante da possibilidade de melhorar a qualidade de vida da população, diretamente por meio do aumento da renda, do emprego e/ou da melhoria na oferta de serviços, ou indiretamente mediante os desdobramentos dos meios diretos ou pelo fortalecimento da cultura local e conservação do meio ambiente (MEDEIROS et al., 2015; CAMILO; BAHL, 2017).

Cada local tem vulnerabilidades e potencialidades, sob diversas perspectivas social, cultural, política, ambiental e econômica. Para Cunha (2008), os atrativos turísticos, como cachoeiras, praias, museus, grupos de cultura e comidas típicas, são elementos que motivam a visitação turística. No entanto, é necessário haver um agente impulsionador para desencadear o processo de produção do espaço a partir do potencial turístico local.

Neste artigo, potencial turístico se refere à perspectiva futura de um local ofertar atividades a partir dos seus recursos turísticos. Por sua vez, recursos turísticos são elementos passíveis de exploração pelo turismo que se encontram na condição de matéria prima. Uma vez estruturados e aptos para o desenvolvimento de atividades, esses recursos se tornam atrativos turísticos e são considerados parte da oferta (GOMES, 2019).

Sendo o turismo um fenômeno espacial, com 
elementos geolocalizados, seu comportamento no espaço geográfico pode ser analisado por meio de técnicas de geoprocessamento, identificadas como análise geoespacial (FERREIRA, 2014). Trata-se de uma abordagem quantitativa da pesquisa geográfica, que tem proporcionado gradualmente uma mudança de paradigma no estudo do espaço geográfico, devida à incorporação de novas tecnologias (PAUL; JHA, 2021), inclusive aplicado ao turismo. São exemplos a autocorrelação espacial, o índice de contiguidade, a probabilidade de interação espacial e a interpolação espacial.

A autocorrelação espacial é uma medida da dependência espacial de uma variável geográfica em comparação consigo mesma. No espaço geográfico é esperado que os fenômenos sejam tão mais semelhantes quanto mais próximos estiverem entre si (lei de Tobler). Portanto, a relação de vizinhança entre os elementos geolocalizados é entendida como uma propriedade constituidora desse espaço.

Para o cálculo da autocorrelação espacial, por meio do índice I de Moran, cria-se uma matriz ponderada de conectividade binária, na qual municípios adjacentes com ocorrência da variável recebem peso 1 e municípios vizinhos sem ocorrência dessa variável recebem peso 0 . Portanto, sempre é considerado o relacionamento da entidade com os seus vizinhos (BIVAND et al., 2013; LUZARDO et al., 2017).

Se a autocorrelação espacial é positiva, significa que há forte organização espacial, ou seja, contém subespaços onde se agrupam valores similares. Já em casos de autocorrelação espacial negativa, predomina a organização de pontos próximos com valores muito diferentes entre si. Autocorrelação espacial nula indica a ausência de dependência espacial (FERREIRA, 2014). No turismo, segundo Rivero (2008), a autocorrelação espacial pode indicar a difusão ou concentração de fluxo turístico no espaço e auxiliar na gestão e planejamento do turismo, sobretudo para apontar possibilidades de expansão geográfica das atividades.

Para validar o resultado de I, calcula-se o pvalor para identificar o seu grau de significância estatística. Portanto, quando o I > 0 e p-valor < 0,05 (ou $95 \%$ de significância) aceita-se a hipótese de que há contiguidade e pode-se afirmar que há dependência locacional entre os eventos (LUZARDO et al., 2017).

Para além da autocorrelação espacial, que se ocupa de analisar o comportamento da variável, a probabilidade de interação espacial é uma técnica para modelar a dinâmica entre variáveis que motivam o indivíduo a se deslocar entres lugares (FERREIRA, 2014). A probabilidade de haver interação espacial entre duas localidades depende da existência de impedâncias geográficas ou de fatores facilitadores, que são intrínsecos ao valor da variável.

No turismo, considerando-se que os atrativos são os elementos motivadores das visitações (CUNHA, 2008), as variáveis capazes de descrever uma probabilidade de interação espacial devem incluir também propriedades espaciais, como distâncias, padrões espaciais e características geográficas.

\section{MATERIAL E MÉTODOS}

\section{Área de Estudo}

O Nordeste Brasileiro (NEB) é composto por 9 unidades da federação e 1.794 municípios. Segundo o Instituto Brasileiro de Geografia e Estatística (IBGE,c2017), a população do NEB, estimada para 2020, foi de 57.374.243 habitantes; as cinco maiores capitais da região, com população maior que 1 milhão, são: Salvador, com 2.886.698 habitantes; Fortaleza, com 2.686.612 habitantes; Recife, com 1.653.461 habitantes; São Luís, com 1.108.975 habitantes; e Maceió, com 1.025.360 habitantes. O índice de desenvolvimento humano das capitais, em 2010, listado por ordem decrescente foi: Recife $(0,772)$, Aracaju (0,770), São Luís $(0,768)$, Natal $(0,763)$ e João Pessoa $(0,763)$ (PNUD Brasil; IPEA; FJP, 2020).

Sobre o Produto Interno Bruto (PIB), a região nordeste produziu, em 2018, aproximadamente $\mathrm{R} \$ 1$ trilhão em riquezas, correspondendo a $14,3 \%$ do total produzido no país (IBGE, 2018). Com relação ao turismo, a participação do setor no PIB total do país em 2018 foi de 8,1\% e ocupou 6,9 milhões de postos de trabalho (BRASIL, 2019), dado que coloca o turismo como um importante componente da economia do país.

Localizada no sertão do estado da Paraíba, a Região Geográfica Imediata de Princesa Isabel (RGIPI) foi utilizada para a aplicação do índice de autocorrelação espacial e probabilidade de interação em escala local, fazendo-se um recorte geográfico de uma região de pequeno porte e pouco desenvolvida do sertão paraibano, para analisar o quadro de fluxo e oferta turísticos em um contexto geográfico específico.

A RGIPI é formada pelos municípios de Juru, Tavares, Princesa Isabel, São José de Princesa e Manaíra, cujo polo é Princesa Isabel, com aproximadamente 23 mil habitantes e Índice de Desenvolvimento Humano Municipal (IDHM) de 0,606, considerado IDHM médio (IBGE, 
c2017; PNUD Brasil; IPEA; FJP, 2020).

A escolha pela RGIPI se justifica pelo baixo desenvolvimento no geral, mas também por Princesa Isabel ter sido palco de um movimento histórico nacional (a Revolta de Princesa, em 1930) (PRINCESA, 2010), além de estar localizada em uma região serrana, caracterizada como brejo de altitude, com paisagens cênicas e ainda assim apresentar um turismo incipiente -, vizinha ao município de Triunfo (PE), onde o turismo possui atividades consolidadas, mas distante das capitais e das grandes cidades nordestinas.

\section{Material}

Esta pesquisa fez uso de dados secundários para a observação da contiguidade espacial da oferta turística e do índice de probabilidade de interação espacial entre localidades receptoras, quais sejam: população estimada para 2020 (IBGE, c2017); renda per capita por município em 2010 (IBGE, 2010); dados colaborativos sobre atrativos turísticos dos estados do NEB, disponíveis na plataforma TripAdvisor (c2021)uma das mais acessadas por turistas de todo o mundo -, e quantidade de empreendimentos de turismo (agências de turismo, casas de espetáculo, centro de convenções, apoio ao turismo, guias, locadoras de veículos, hospedagem, organizadores de eventos, parque aquático, parque temático, prestador especializado em segmentos turísticos, alimentação e transportadoras) registrados no Cadastur (BRASIL, s.d.)- plataforma do governo federal para o cadastro de empreendimentos de turismo -, referentes ao quarto trimestre de 2019, período pré-pandemia da COVID-19.

Os softwares utilizados foram: (1) o editor de planilhas WPS Office Planilhas; (2) a linguagem $\mathrm{R}$ 4.0.3 (R CORE TEAM, 2009), por meio do software R Studio 1.4; e (3) Sistema de Informação Geográfica (SIG) QGIS 3.10 (QGIS.org, 2020).

\section{Métodos}

Nesta pesquisa quantitativa e descritiva, a primeira etapa correspondeu à preparação dos dados, a exemplo da junção de dados socioeconômicos com dados geográficos no $\mathrm{R}$ 4.0.3 e cômputo das distâncias euclidianas entre todas as sedes municipais do NEB, no QGIS 3.10.

$\mathrm{Na}$ etapa de processamento, a autocorrelação espacial foi calculada para um mapa binário, sobre polígonos, utilizando-se como entrada os dados de empreendimentos turísticos do Cadastur, validados pela correlação de Pearson com o quantitativo de atrativos turísticos por estado. Levou-se em consideração os graus de vizinhança entre as feições que apresentaram manifestação positiva da variável em questão, juntamente com o cálculo da sua covariância e variância. Foi utilizado o Índice I Global de Moran - Equação 1 (MORAN, 1948; 1950 citado por FERREIRA, 2014).

$$
I=\frac{n}{2 k}\left(\frac{\sum_{i=1}^{n} \sum_{j=1}^{m} \delta_{i, j}\left(z_{i}-\mu\right)\left(z_{j}-\mu\right)}{\sum_{i=1}^{n}\left(z_{i}-\mu\right)^{2}}\right) \text { (Eq. 1) }
$$

Em que: $n=$ quantidade de unidades espaciais; $k=$ quantidade de junções possíveis; $\mu=$ média dos eventos binários; $\delta_{i, j}=$ conectividade binária entre as unidades espaciais $i$ e $j ; z_{\mathrm{i}}$ e $z_{\mathrm{j}}=$ quantidade de ocorrência da variável em questão nas unidades espaciais $i$ e $j$.

O índice I Global foi calculado por meio da função moran.test(), pacote spdep, no $\mathrm{R}$, bem como a função poly $2 n b$ () foi utilizada para o cômputo dos vizinhos de cada polígono, e foi gerado um correlograma pela função sp.correlogram(). O objetivo, com isso, foi avaliar o grau de autocorrelação espacial da oferta de serviços de turismo no NEB.

Em escala local, na qual o índice I (Eq. 2) é calculado para cada unidade geográfica do mapa (município) em relação às suas vizinhas, foi utilizada a função localmoran(). Foram gerados mapas de significância estatística e do índice I Local. Vale ressaltar que tanto o I Global quanto o I Local exigem como entrada a variável e uma lista de pesos calculados para cada vizinho da unidade geográfica, obtida pela função nb2listw().

$$
I_{i}(d)=\frac{x_{i}-\mu}{\sum_{i}\left(x_{i}-\mu\right)^{2}} \sum_{j} w_{i, j}(d)\left(x_{j}-\mu\right)
$$

Em que: $I_{i}=$ índice I local de Moran na posição $i$; $x_{i}=$ valor da variável na posição $i ; \mu=$ média da variável; e $w_{i, j}=$ matriz ponderada binária espacial.

O indicador da probabilidade de interação espacial (Índice “ $a$ ”) foi obtido pela razão entre os empreendimentos de turismo no destino e as distâncias entre as localidades de origem e destino, calculadas no SIG, ponderada pela população e renda per capita - adaptado de Ferreira (2014) (Equação 3).

$$
a_{i, j}=\frac{S_{j}}{d_{i, j}^{\lambda}}
$$


Em que: $a_{i, \mathrm{j}}=$ possibilidade de interação entre duas localidades $i$ e $j ; S_{j}=$ quantidade de estabelecimentos comerciais de turismo na localidade de destino; $d_{i, j}=$ distância entre $o$ local de origem $i$ e o de destino $j ; \lambda=$ parâmetro de ponderação (quanto maior mais atenua o efeito da distância entre os locais $i$ e $j$ sobre a possibilidade de interação) (Equação 4).

$$
\lambda=\frac{1}{\left(r_{i} / P_{i}\right)+\left(r_{j} / P_{j}\right)} \times 100
$$

Em que: $r=$ renda per capita; e $P=$ população.

A partir disso, foi aplicado o interpolador espacial Inverso do Quadrado da Distância (IQD), dado pela Equação 5 (SILVA, 2018), para produzir uma superfície contínua com valores estimados do índice " $a$ " nos locais sem dados amostrados, de modo a possibilitar a identificação de zonas de ofertas turísticas e analisar os fluxos.

$$
Z_{0}=\frac{\sum_{i=1}^{n}\left(z_{i} / d_{i j}^{2}\right)}{\sum_{i=1}^{n}\left(1 / d_{i j}^{2}\right)}
$$

Em que: $Z_{0}=$ estimativa do valor de $Z$ no ponto 0 , com localização $x, y ; z_{i}=$ valor amostrado de $z$ no ponto $i ; d_{i j}=$ distância euclidiana entre o ponto $O$ (estimado) e o ponto $i$ (amostrado).

\section{RESULTADOS E DISCUSSÃO}

\section{Análise da oferta turística no NEB}

Os dados de empreendimentos (Cadastur) se mostraram altamente correlacionados com os dados colaborativos de atrativos turísticos (Tripadvisor) nos estados do NEB, alcançado $\mathrm{r}=$ 0,9610, validando assim o uso dos dados do Cadastur, oficiais do país, nesta análise. Inicialmente, 19.786 empreendimentos e 6.161 atrativos foram contabilizados e localizados nas unidades da federação às quais estão vinculados (Figura 1). Desses, 465 não apresentaram vinculação a um município.

Figura 1 - Ocorrência dos atrativos e estabelecimentos turísticos nos estados do NEB.

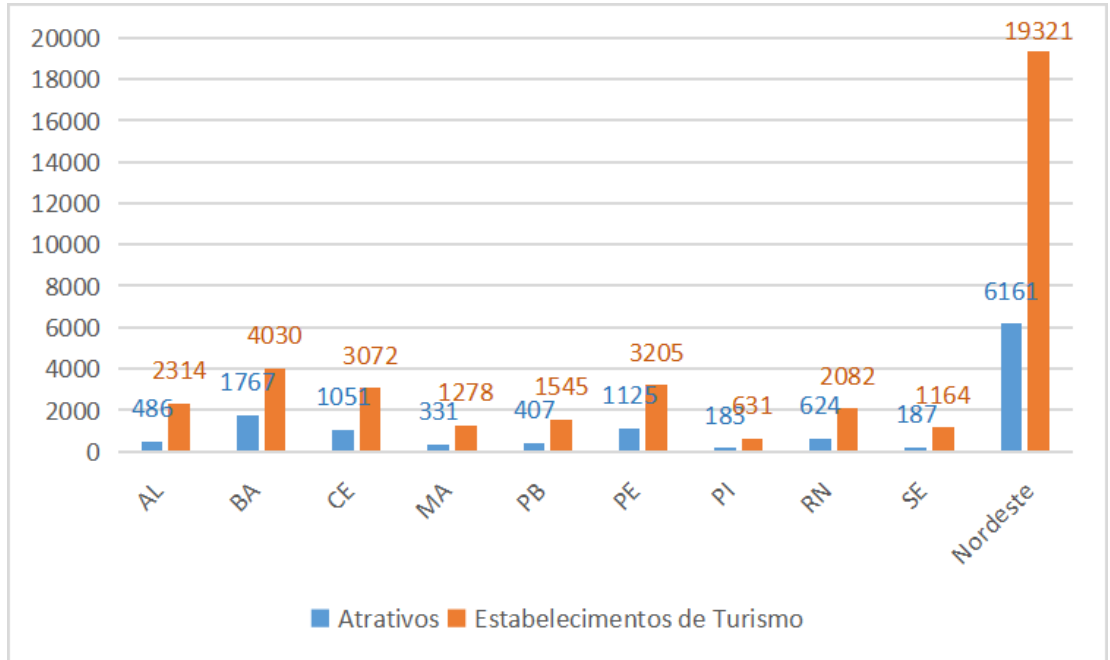

Fonte: BRASIL (s.d.); Tripadvisor (c2021). Org. dos autores (2021).

A observação do mapa temático da distribuição espacial desses empreendimentos pelo NEB (Figura 2) permite perceber que os municípios com mais de 500 empreendimentos estão localizados na faixa litorânea, que, por correlação, é onde a oferta de atividades turísticas é maior (COSTA, 2012). Os estados da Bahia, Piauí e Maranhão possuem, visivelmente no interior, os maiores vazios de empreendimentos cadastrados.

Ainda, verifica-se que na RGIPI, em destaque na Figura 2, a predominância das classes 'vazia' e apenas 1 empreendimento do ramo da hospedagem, em Princesa Isabel, subestimando o potencial turístico local. Fica então evidente a escassa infraestrutura de apoio e serviços de turismo na região.

Dos 1.794 municípios nordestinos, 774 não possuem estabelecimentos comerciais de turismo cadastrados no Cadastur; 268 possuem apenas 1; 182 municípios possuem 2; 85 possuem $3 ; 78$ possuem 4 e 51 possuem 5 empreendimentos. Esses correspondem a $37 \%$ da totalidade, ou seja, muitos municípios com 
pouquíssima ou nenhuma atividade turística sendo desenvolvida.

Figura 2 - Mapa da distribuição dos empreendimentos comerciais de turismo no NEB e na Região Geográfica Imediata de Princesa Isabel.

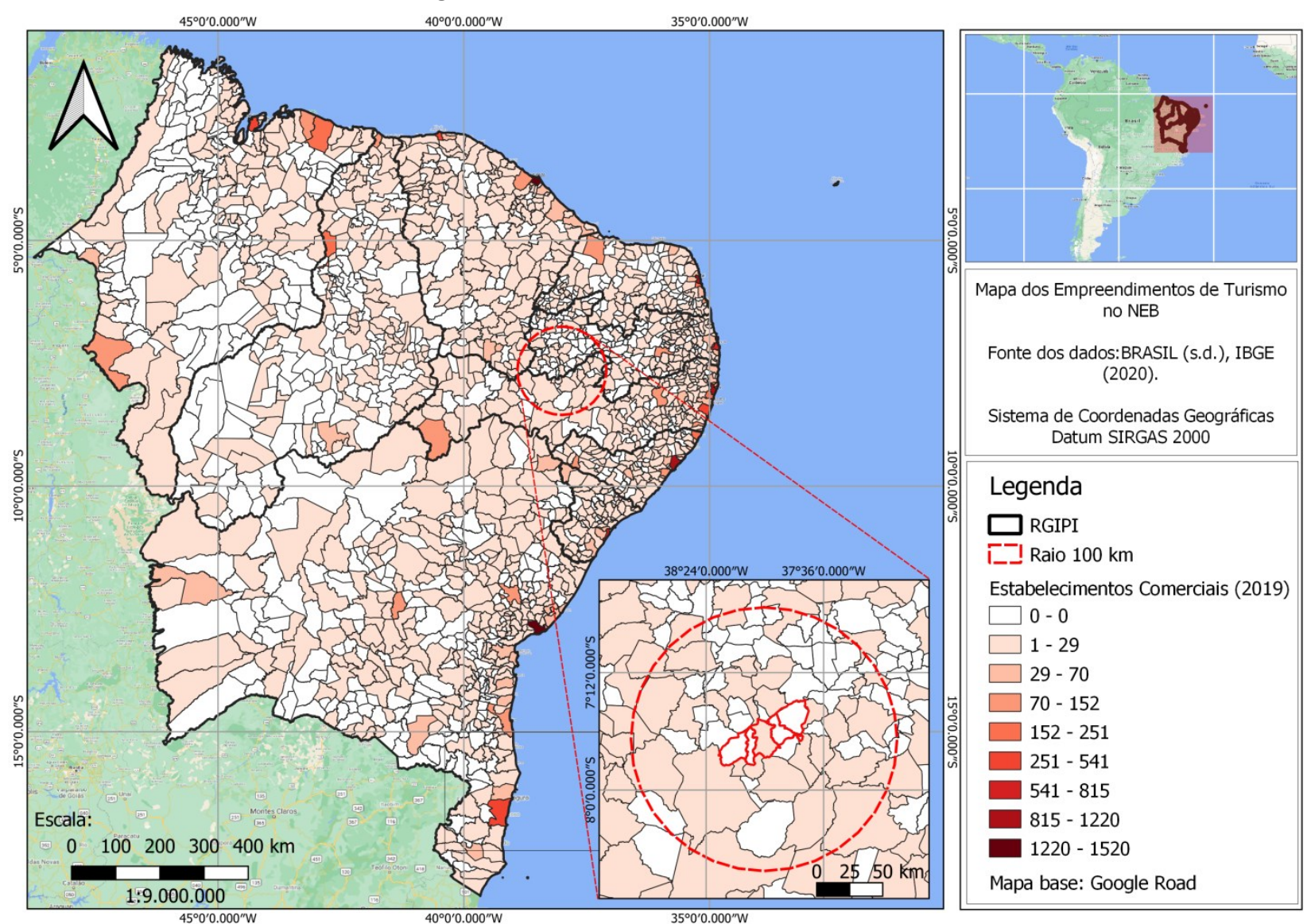

Fonte: BRASIL (s.d.); IBGE (c2017); Org. dos Autores (2021).

No total foram identificados 19.321 empreendimentos vinculados a pelo menos um município no Nordeste, verificando-se uma média de aproximadamente 11 empresas por município e desvio padrão de 75,3 empresas, que é um indicativo de alta desigualdade na distribuição espacial das atividades turísticas pelo NEB e, consequentemente, na produção do espaço; sendo as capitais as maiores ofertantes de serviços turísticos, lideradas por Fortaleza com 1.520 empreendimentos.

O estado da Bahia possui $21 \%$ desses, seguido por Pernambuco (17\%) e Ceará (16\%).
$\mathrm{Na}$ média de estabelecimentos turísticos, os estados que apresentaram maior estrutura comercial de apoio foram Alagoas (22,7), Pernambuco $(17,3)$ e Ceará $(16,7)$. O desvio padrão para essas médias também indica distribuição espacial desigual nos estados, com maiores quantidades nas capitais.

De acordo com a ocorrência dos tipos de serviços ofertados no NEB (Figura 3), a maior parte é prestada por agências de turismo, serviços de guia, hospedagem e transportadora turística, que atendem a uma demanda social elementar pelo consumo do espaço. 
Figura 3 - Ocorrência dos tipos de serviços turísticos ofertados no NEB.
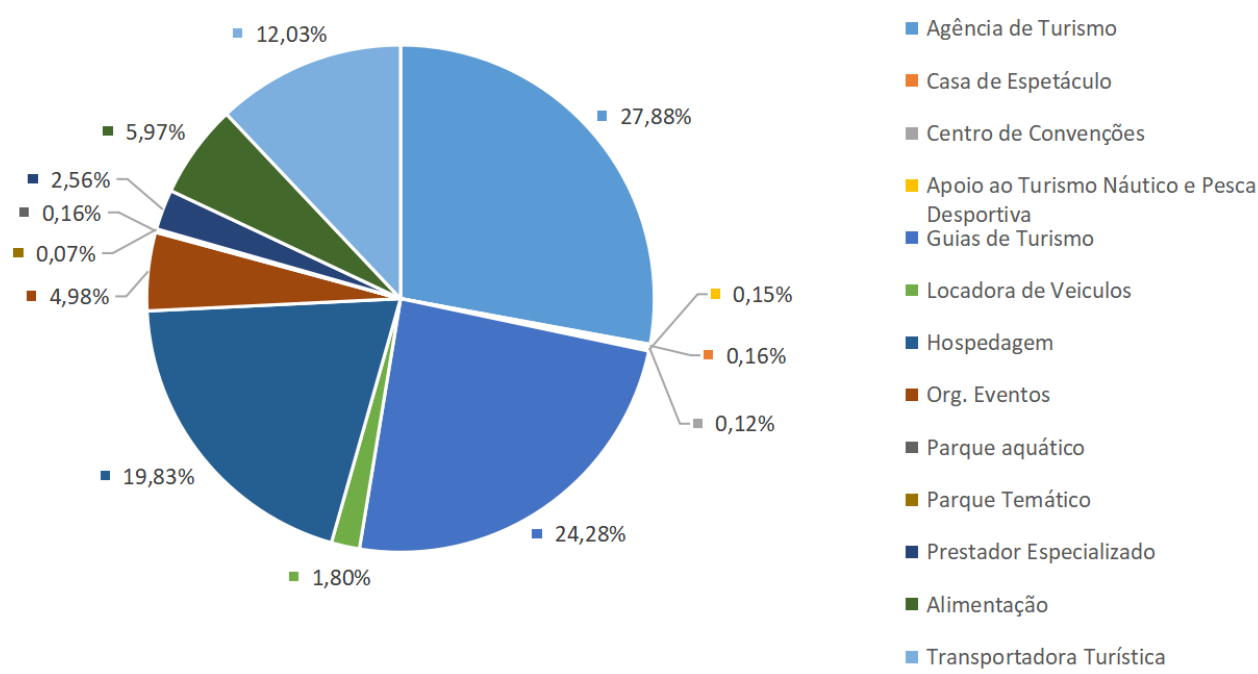

Fonte: BRASIL (s.d). Org. dos Autores (2021).

Há também diversidade na oferta, ocasionada pelas vocações locais, que, a depender da constituição do espaço, ensejam a existência de equipamentos específicos, como parques aquáticos e apoio ao turismo náutico e pesca desportiva nos municípios litorâneos ou que possuem recursos hídricos aproveitados para essa finalidade.

O gráfico que se apresenta na Figura 3 é um retrato do turismo no último trimestre de 2019 no NEB e sintetiza um desdobramento da evolução histórica na construção dos espaços turísticos da região. Nesse sentido, Muniz e Castro (2018) utilizaram o município de Carolina (MA) para demonstrar que a contextualização histórica local apresenta variáveis que possibilitam compreender o momento e os rumos da produção daquele espaço. Sob a lógica de mercado dominante, há a provocação de uma dinâmica de movimentação socioeconômica e exploração ambiental - por meio da criação e manutenção de empreendimentos, emprego e renda, inclusive motivados pela concorrência na oferta, mas também via práticas de turismo natural - que desenvolve os elementos fixos e os fluxos locais e contribui, a depender da sua constituição, para a turistificação do espaço.
Também se destaca nesse processo o suporte estatal para impulsionar a produção do espaço, a exemplo do Prodetur/NE, investindo na infraestrutura, na promoção da gestão e propaganda dos lugares e da conservação ambiental, mas desenvolvendo as regiões de maneira desigual (ALMADA, 2020; SILVA et al., 2021).

\section{Autocorrelação espacial e Contiguidade dos Empreendimentos de Turismo no NEB}

A autocorrelação espacial dos empreendimentos de turismo (índice I Global) obtida foi $\mathrm{I}=0,0916$ e $p=1,2 e-12$, indicando ausência de contiguidade da oferta turística, confirmada pela significância estatística. O correlograma da variável empreendimentos de turismo no NEB (Figura 4) evidenciou que os valores do índice I Global se situaram próximo de 0 e estacionam a partir do lag 2. No lag 1 se encontra a maior contiguidade espacial (que já é baixa), seguida da permanência muito próxima em torno de 0 . Isto é, com o aumento da distância há a estabilização da independência espacial. 
Figura 4 - Correlograma dos estabelecimentos turísticos oficialmente cadastrados.

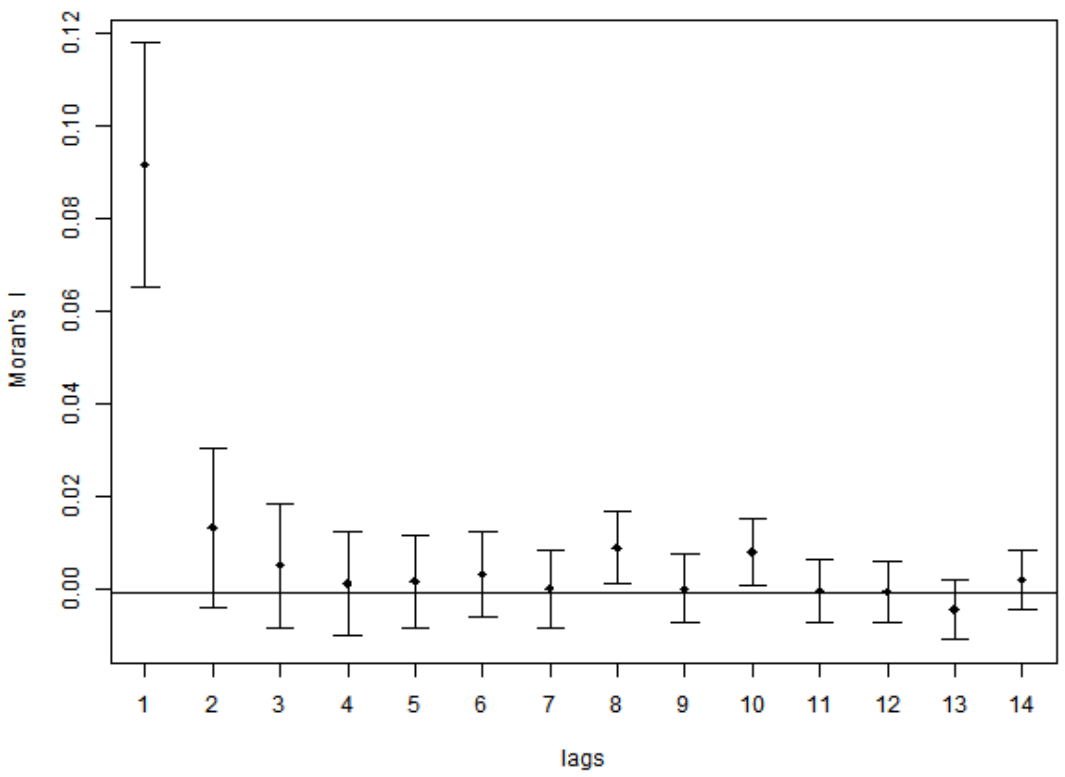

Fonte: Os autores (2021).

Por sua vez, o Índice I Local de Moran em todo o NEB ficou entre -1 e 0 na maioria dos municípios do NEB, isto é, próximo de independência espacial das atividades turísticas em relação aos seus vizinhos (FERREIRA, 2014). Os maiores valores de I
Local, acima de 1 (contiguidade da oferta turística), foram localizados na faixam litorânea do NEB e confirmados pelo p-valor (Figura 5).

Figura 5 - Mapa do Índice I Local e Significância Estatística sobre empreendimentos de turismo no NEB e na RGIPI.

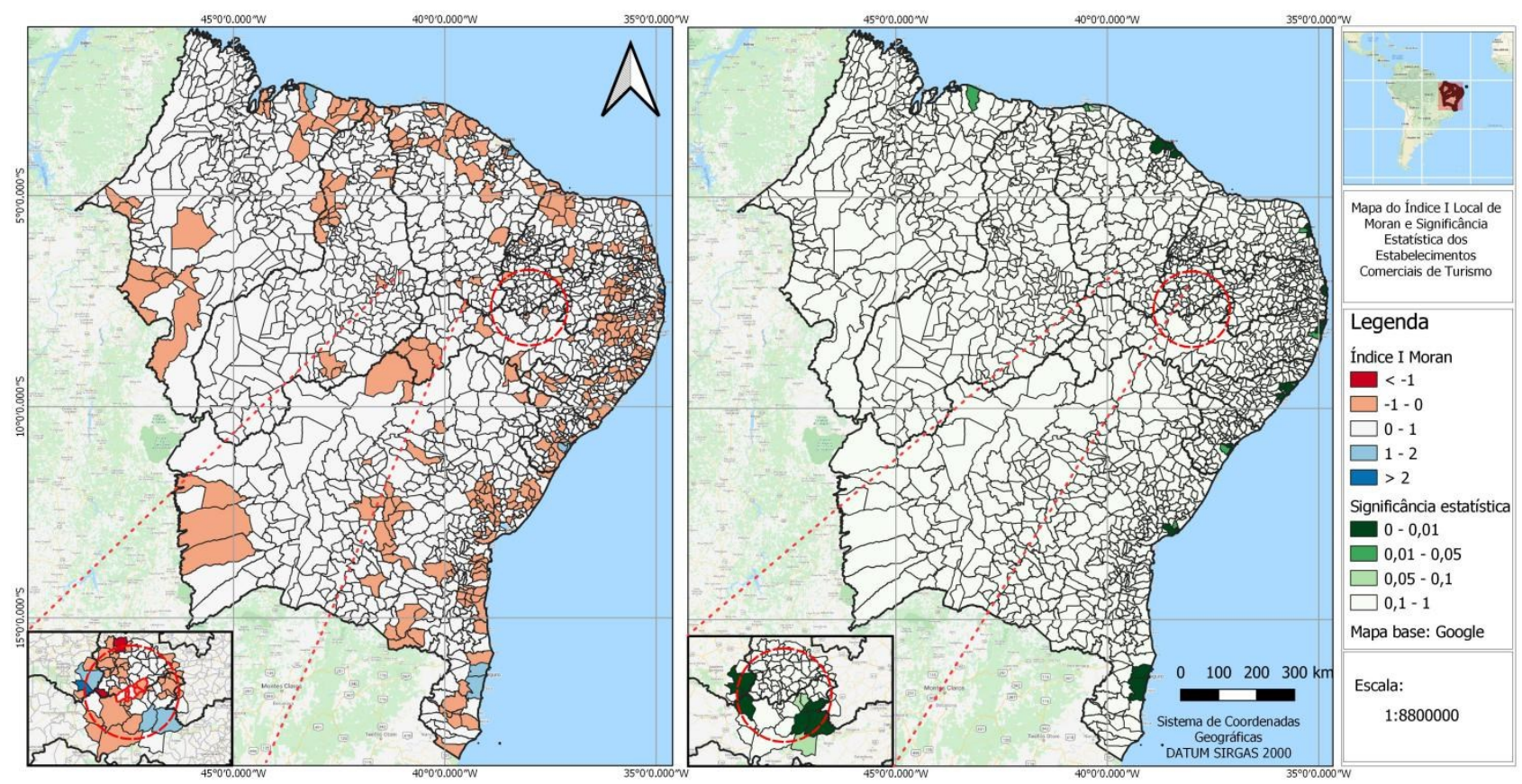

Fonte: Os autores (2021).

$\mathrm{Na}$ RGIPI, o Índice I Local destaca a existência de dois agrupamentos com contiguidade espacial (tons azuis), com significância estatística relevante (Figura 5). Vale ressaltar que esse recorte geográfico considerou municípios distantes até $100 \mathrm{~km}$ da RGIPI e produziu resultado diferente de quando se incluiu todos os municípios do Nordeste.

Pode-se afirmar que na maioria do território nordestino, especialmente no interior e na 
RGIPI, não há oferta contínua relevante de atividades turísticas, mas existem poucas e pequenas zonas de contiguidade espacial dessa oferta. Isso mostra que existe turismo local, embora geograficamente disperso, e indica possibilidades de integração zonal e expansão do turismo para municípios adjacentes. Evidenciase assim a importância da análise em escala global e local (RIVERO, 2008).
O mapa de associação espacial do índice I Local (LISA) sobre empreendimentos de turismo no NEB e na RGIPI permitiu a identificação de clusters/zonas turísticas, no qual são apresentadas classes de indicadores de similaridade (High-High, HH; High-Low, HL; Low-High, LH; Low-Low, LL) para cada município (Figura 6).

Figura 6 - Mapa de associação espacial do índice I Local no NEB e na RGIPI.

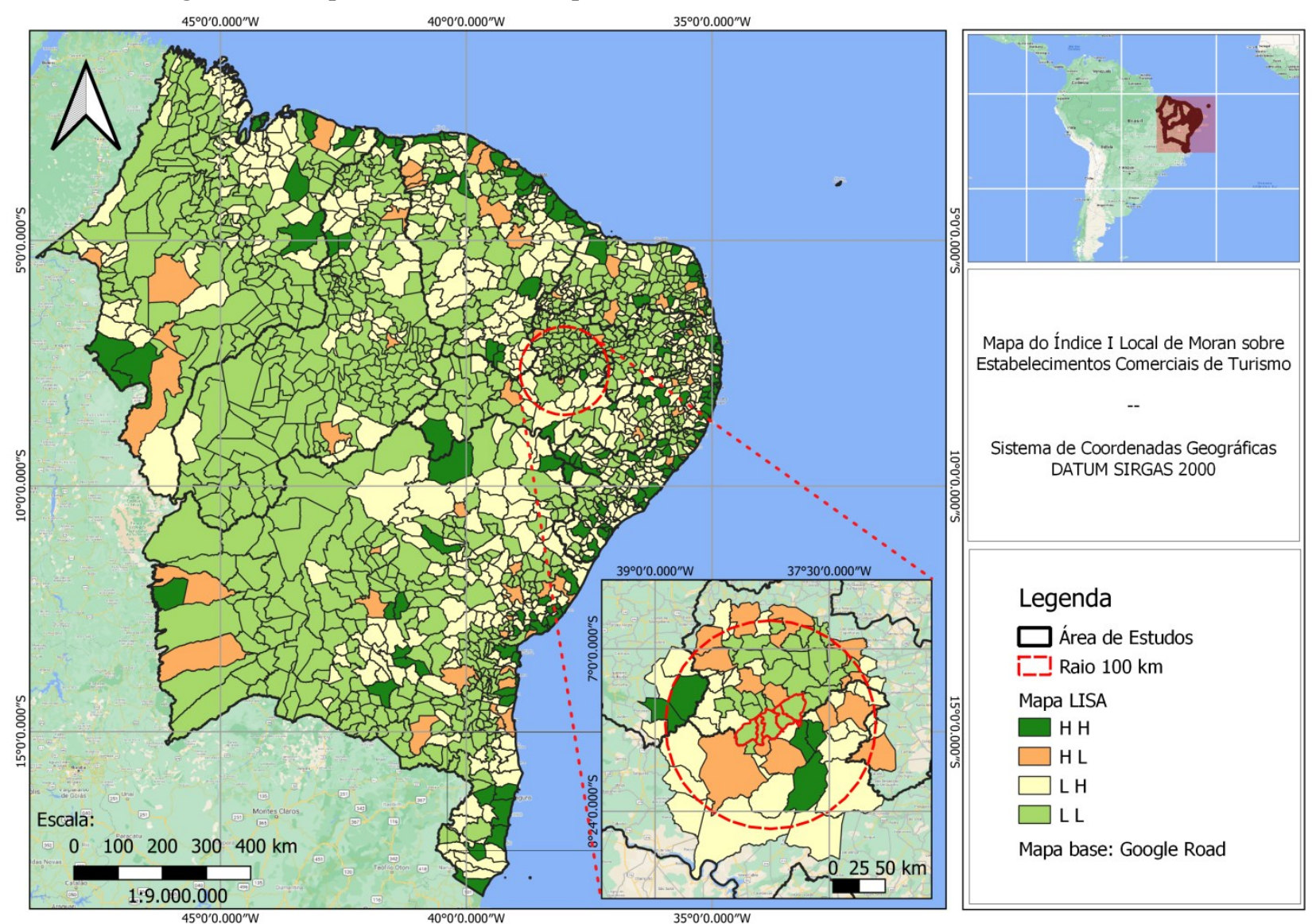

Fonte: Os autores (2021).

O indicador LL possui perceptíveis agrupamentos distribuídos no interior do NEB, significando semelhança e contiguidade para pouca ou nenhuma quantidade de infraestrutura turística. Isto é, nesses clusters, a infraestrutura para o turismo é pequena e menor que a média global.

Observando a partir da RGIPI, percebe-se que LL aponta para o agrupamento de 31 municípios, enquanto 5 municípios formam duas zonas do indicador $\mathrm{HH}$, exatamente aqueles com quantidade de empreendimentos turísticos maior que a média global, indicando um potencial de expansão das atividades turísticas.

A ocorrência dos indicadores HL e LH implica ausência de contiguidade, dissimilaridade de valores e isolamento ou concentração de atividades turísticas em locais específicos, sem propagação dessas. Na prática, é um indicador geográfico de restrição da visitação, pois nos municípios ou localidades vizinhas não há oferta turística.

Apesar do indicativo, a disseminação de atividades turísticas para municípios vizinhos depende fortemente de investimentos públicos, sobretudo para a melhoria da infraestrutura física, gestão para a promoção de atividades turísticas e critérios claros para distribuição espacial de recursos financeiros (SILVA et al., 2021). 


\section{Análise do Índice "a"}

Para o índice " $a$ " produziu-se uma lista com 16.146 possibilidades de interação, sendo consideradas apenas as capitais como unidades emissoras de turistas. O Índice " $a$ " sugere as maiores probabilidades de recepção de turistas nas capitais, mais estruturadas para o turismo, mais populosas e com maior renda per capita, superando até o parâmetro distância entre destino e origem em muitas interações.

Decerto o índice não concretiza as probabilidades apontadas, mas é uma importante fonte de informação para o planejamento turístico no destino. Os 10 maiores valores de " $a$ " ocorreram entre os municípios listados na Tabela 1

Tabela 1- Índice de probabilidade de interação (" $a$ ”) entre municípios do NEB.

\begin{tabular}{ccccc}
\hline Origem $(\boldsymbol{i})$ & Destino $(\boldsymbol{j})$ & $\mathbf{d}_{\boldsymbol{i}, \boldsymbol{j}} \mathbf{( \mathbf { k m } )}$ & $\boldsymbol{\lambda}$ & “ $\boldsymbol{\boldsymbol { }}$ \\
\hline Recife & Fortaleza & 634,854409 & 0,000566 & 1514,456193 \\
Natal & Fortaleza & 434,706683 & 0,000636 & 1514,132011 \\
João Pessoa & Fortaleza & 562,659225 & 0,000639 & 1513,854405 \\
Aracaju & Fortaleza & 817,867053 & 0,000617 & 1513,713823 \\
Salvador & Fortaleza & 1034,332610 & 0,000624 & 1513,429706 \\
Teresina & Fortaleza & 493,156586 & 0,000699 & 1513,416848 \\
São Luís & Fortaleza & 649,119053 & 0,000693 & 1513,188526 \\
Maceió & Fortaleza & 734,968633 & 0,000694 & 1513,052498 \\
Aracaju & Salvador & 284,137721 & 0,000573 & 1374,537068 \\
Recife & Salvador & 681,475369 & 0,000528 & 1374,249504
\end{tabular}

Fonte: Os autores (2021).

Os 20 municípios com maiores probabilidades de receber turistas, partindo das capitais do Nordeste, são: Fortaleza (CE), Salvador (BA), Maceió (AL), Recife (PE), Natal $(\mathrm{RN})$, João Pessoa (PB), Aracaju (SE), Porto Seguro (BA), São Luís (MA), Jijoca de Jericoacoara (CE), Ipojuca (PE), Parnamirim $(\mathrm{RN})$, Jaboatão dos Guararapes (PE), Teresina (PI), Olinda (PE), Maragogi (AL), Barreirinhas (MA), Campina Grande (PB), Feira de Santana (BA) e Santo Amaro do Maranhão (MA). Municípios nacionalmente conhecidos pela atratividade turística, como Tibau do Sul (RN), Lençóis (BA), Ilhéus (BA), Tamandaré (PE) e Marechal Deodoro (AL), ficaram entre os 30 municípios com maiores chances de receber turistas oriundos das capitais.

Aplicando-se ao caso da RGIPI, para um raio de $100 \mathrm{~km}$ do seu entorno - considerando que distâncias maiores tornariam o destino menos atrativo -, as maiores chances de interações se deram entre municípios próximos. Foram encontrados 340 resultados, dos quais os 10 maiores estão dispostos na Tabela 2 .

Tabela 2 - Dez maiores probabilidades de interação partindo da RGIPI para outros municípios localizados a até $100 \mathrm{~km}$ de distância.

\begin{tabular}{|c|c|c|c|c|}
\hline Origem (i) & Destino (j) & $d_{i, j}(k m)$ & $\lambda$ & "a" \\
\hline Princesa Isabel & Triunfo & 16,612283 & 0,147630 & 9,906459 \\
\hline Princesa Isabel & Afogados da Ingazeira & 39,660159 & 0,152688 & 9,691682 \\
\hline Tavares & Afogados da Ingazeira & 29,603369 & 0,166386 & 9,674694 \\
\hline Juru & Afogados da Ingazeira & 31,244166 & 0,167247 & 9,559873 \\
\hline Manaíra & Triunfo & 14,959683 & 0,167999 & 9,521485 \\
\hline São José de Princesa & Afogados da Ingazeira & 51,335010 & 0,170083 & 8,700344 \\
\hline Tavares & Triunfo & 33,449423 & 0,160398 & 8,542422 \\
\hline Manaíra & Afogados da Ingazeira & 57,578772 & 0,174580 & 8,378035 \\
\hline Juru & Triunfo & 46,003548 & 0,161198 & 8,091911 \\
\hline Princesa Isabel & Serra Talhada & 43,993334 & 0,149898 & 5,103889 \\
\hline
\end{tabular}

Observa-se que o município de Afogados da Ingazeira (PE) aparece frequentemente na lista das maiores interações, mesmo que no entorno de $100 \mathrm{~km}$ não seja o município mais populoso nem o de maior renda per capita, mas é o que possui maior quantidade de empreendimentos turísticos, seguido por Triunfo (PE) (mais próximo), Serra Talhada (PE) (mais populoso e de maior renda per capita), Mauriti (CE) e Itaporanga (PB).

Ao analisar o parâmetro $\lambda$, cujos valores menores implicam em maior peso para o fluxo turístico, percebe-se que a interação Princesa Isabel-Triunfo, Princesa Isabel-Serra Talhada e 
Princesa Isabel-Afogados da Ingazeira são as mais prováveis para o turismo. Para fins não turísticos (comércio, busca por serviços médicos, entre outros), uma constante interação espacial entre Princesa Isabel e Serra Talhada pode ser constatada localmente.

Com esses resultados se observa as consideráveis diferenças entre os valores do índice " $a$ " para uma região com municípios pouco desenvolvidos e para as capitais do Nordeste. Esse fato tem fundamento histórico nas intervenções estatais para a turistificação do NEB, desde a década de 1970, particularmente com as políticas de polarização e indução do turismo, as quais priorizaram algumas zonas em detrimento de outras (DUDA; ARAUJO, 2014).

Identificação de zonas turísticas por meio da interpolação espacial do Indice "a"

O mapa de probabilidade de fluxos turísticos no NEB (Figura 7) foi obtido a partir da aplicação do IQD aos valores do índice " $a$ ", produziu o mapa da Figura 7 e objetivou representar a probabilidade de uma localidade receber turistas. Os tons quentes identificam zonas turísticas no NEB, que correspondem àquelas existentes na realidade, o que permite validar o índice " $a$ ". Como exemplo, pode-se destacar a faixa litorânea do NEB, historicamente favorecida por políticas de turistificação (DUDA; ARAUJO, 2014).

Os destaques no interior do NEB estão no cariri cearense, abrangendo os municípios do Crato, Juazeiro do Norte e Barbalha (Figura 7a); na Bahia, na divisa com Pernambuco, onde se localizam Juazeiro (BA) e Petrolina (PE) (Figura 7b), também na região da Chapada Diamantina, onde é destaque o município de Lençóis (Figura 7c). Nas divisas entre Alagoas e Sergipe, o município de Paulo Afonso (BA), cortado pelo Rio São Francisco e sede de uma das maiores usinas hidrelétricas do país, é um destino turístico consolidado, assim como Piranhas (AL) e Canindé do São Francisco (SE) (Figura 7d); no Piauí destaca-se o entorno da capital Teresina (Figura 7e); e no agreste paraibano, o município de Campina Grande (Figura 7f), onde ocorrem grandes festas juninas.

Figura 7 - Mapa de probabilidade de fluxos turísticos no NEB (índice " $a$ ")
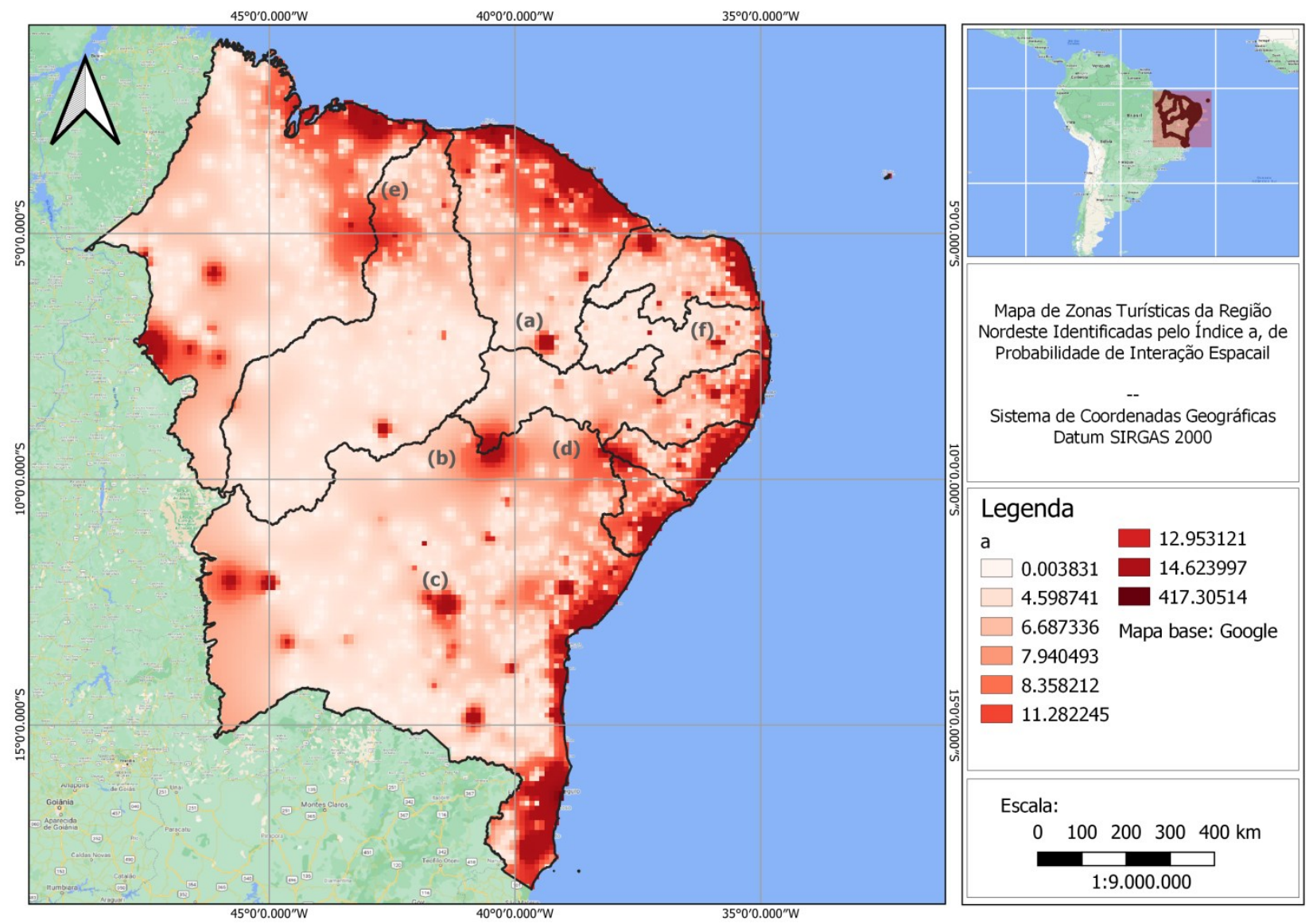

Fonte: Os autores (2021). 
Observa-se ainda que as zonas identificadas estão dispersas no espaço (ausência de autocorrelação espacial), à exceção da faixa litorânea, que é contínua. Além disso, há apenas uma zona no interior do continente conectada à faixa litorânea (Figura 7e), entre Teresina e o litoral do Maranhão, configurando a única extensão territorial do NEB entre o litoral e o interior com alto fluxo de turistas, o que é pouco, dada a extensão da região, e evidencia a subexploração do potencial turístico existente.

\section{CONSIDERAÇÕES FINAIS}

É importante ressaltar que as geotecnologias cumprem papel fundamental no estudo do turismo, enquanto fenômeno espacial que congrega sociedade e ambiente, e subsidiam a tomada de decisões. A análise geoespacial permitiu desvendar padrões espaciais intrínsecos ao desenvolvimento da atividade turística.

Pode-se considerar que as variáveis utilizadas nesta pesquisa foram suficientes para diagnosticar o estado do turismo no território nordestino, sobretudo no interior do continente, revelando a carência de investimentos e as desiguais ofertas turísticas, que se concentram nas capitais.

Também, a análise geoespacial sobre o turismo no NEB mostrou que há espaço para atenuar as severas desigualdades regionais na oferta turística, pela possibilidade de expansão dessa, embora seja necessária uma reconfiguração das políticas de incentivo; e os fluxos convergem para os municípios mais ricos e historicamente favorecidos por políticas públicas.

Com base na escassez de ações públicas e de dados, na falta de padronização para normas cadastrais e inexistência de mapeamentos turísticos sistemáticos, conclui-se que as carências identificadas são decorrentes da falta de estímulos governamentais, em todas as esferas, para o desenvolvimento turístico nos municípios com potencial e para disseminar as zonas turísticas identificadas nesta pesquisa. Esses fatores dificultam um estudo pormenorizado, mas considera-se que os dados e métodos empregados foram capazes de produzir informações de interesse ao desenvolvimento local.

\section{AGRADECIMENTOS}

À Universidade Federal da Paraíba pela oportunidade do desenvolvimento deste trabalho mediante o compartilhamento de conhecimento e estrutura.

\section{REFERÊNCIAS}

ALMADA, J. A. B. de. O turismo no Rio Grande do Norte. Sociedade e Território, Natal, v. 31, n. 2, p.241-262, 2020. https://doi.org/10.21680/21778396.2019v31n2ID19140.

ALVES, L. da S. F.; DANTAS, E. W. C. Turismo e região nordeste brasileira: reconfiguração territorial litorânea da Colônia ao II PND. Geosul, Florianópolis, v. 31, n. 67, p.7-32, 2016. Disponível em:

https://periodicos.ufsc.br/index.php/geosul/article/vi ew/2177-5230.2016v31n61p7/31908. Aceso em: 08 set. 2021.

BENI, M. C. Análise estrutural do turismo. $11^{\mathrm{a}} \mathrm{ed}$. Rev. e atualizada. São Paulo: Editora Senac São Paulo, 2006.

BIVAND, R. S.; PEBESMA, E.; e GÓMEZ-RUBIO, V. Applied spatial data with R. $2^{\text {a }}$ ed. New York: Springer, 2013. https://doi.org/10.1007/978-1-46147618-4

BRASIL. Ministério do Turismo. Cadastur: fazendo o turismo legal. s.d. Disponível em: https://cadastur.turismo.gov.br/. Acesso em: 13 set. 2021.

BRASIL. Ministério do Turismo. Cresce a participação do turismo no PIB nacional. Brasília, 07 de mar. de 2019. Disponível em: http://www.turismo.gov.br/\%C3\%BAltimasnot\%C3\%ADcias/12461-cresce-verificar foaparticipa $\%$ C3\%A7\%C3\%A3o-do-turismo-no-pibnacional.html. Acesso em: 19 set. 2020.

CAMILO, I; BAHL, M. Desenvolvimento do turismo baseado em elementos culturais. Turismo \& Sociedade, Curitiba, v. 10, n. 1, p.1-12, 2017. http://dx.doi.org/10.5380/tes.v10i1.52187.

COSTA, C. R. R. da. Turismo, produção e consumo do espaço litorâneo. Geografia em Quetão, Online, v. 5, n. $1, \quad$ p.147-162, 2012. https://doi.org/10.48075/geoq.v5i1.5078.

CUNHA, L. Avaliação do Potencial Turístico. Cogitur, Journal of Tourism Studies, [S.l.], v. 1, n. 1, jan. 2008. Disponível em: https://recil.grupolusofona.pt/handle/10437/384. Acesso em: 09 set. 2021.

DUDA, J. I. de M.; ARAUJO, L. M. de. Polos de turismo no nordeste do Brasil: crescimento, desenvolvimento e escassez de conhecimento. Caderno Virtual de Turismo. Rio de Janeiro, v. 4, n. 3, p.204-218, dez. 2014. Disponível em: http://www.ivt.coppe.ufrj.br/caderno/index.php/cad erno/article/view/846. Acesso em: 13 set. 2021.

FERREIRA, M. C. Iniciação à análise espacial: teoria, técnicas e exemplos para 
geoprocessamento. $1^{\mathrm{a}}$ ed. São Paulo: Editora Unesp, 2014.

GOMES, C. S. C. D. Potencial turístico de destinos: proposta de um modelo de avaliação com base nos recursos endógenos. 2019. 180f. Tese (Doutorado em Turismo) - Universidade Federal do Rio Grande do Norte, Natal, 2019.

IBGE. Instituto Brasileiro de Geografia e Estatística. Censo demográfico. Online, 2010. Disponível em: https://censo2010.ibge.gov.br/. Acesso em: 03 jul. 2020.

IBGE. Instituto Brasileiro de Geografia e Estatística. IBGE Cidades, c2017. Disponível em: https://cidades.ibge.gov.br/. Acesso em: 28 ago. 2021

IBGE. Instituto Brasileiro de Geografia e Estatística. Sistema de contas regionais. Brasil, 2018. Disponível em: https://biblioteca.ibge.gov.br/visualizacao/livros/liv 101765_informativo.pdf. Acesso em: 21 ago. 2021.

LUZARDO, A. J. R.; CASTAÑEDA FILHO, R. M.; RUBIM, I. B. Análise espacial exploratória com o emprego do índice de Moran. GEOgraphia. Niterói, v. $19, \quad$ n. $40, \quad$ p.161-179, 2017. https://doi.org/10.22409/GEOgraphia2017.v19i40.a 13807.

MEDEIROS, J. L. de; SILVA, E. G. da; ARAUJO, F. S. G.; BARRETO, L. M. T. da S. Comprometimento dos stakeholders no turismo: uma análise do desenvolvimento do Geoturismo no município de Gurjão (Paraíba, Brasil). Turismo \& Sociedade, Curitiba, v. 8, n. 1, p.38-57, 2015. http://dx.doi.org/10.5380/tes.v8i1.34495.

MUNIZ, G. P. S.; CASTRO, C. E. de. A produção do espaço e o turismo em Carolina - Maranhão, Brasil. Interespaço, Revista de Geografia e Interdisciplinaridade, Grajaú, v. 4, n. 15, p.82105, set./dez., 2018. http://dx.doi.org/10.18764/24466549.v4n15p82-105.

PAUL, K.; JHA, V. C. Paradigm shifts in geographical research and geospatial applications. Sociedade \& Natureza, Uberlândia, v. 33, 2021. https://doi.org/10.14393/SN-v33-2021-59651.

PNUD BRASIL; IPEA; FJP. Atlas do Desenvolvimento Humano no Brasil. 2020. Disponível em: http://www.atlasbrasil.org.br/consulta/planilha. Acesso em: 09 set. 2021.

PRINCESA do Sertão. Direção: Deraldo Goulart. 1 vídeo. (116 min.). Brasília: TV Senado, 2010. Disponível em: https://www.youtube.com/watch?v=SPiPD-3htJo.
Acesso em: 09 set. 2021.

QGIS.org. QGIS Geographic Information System. Open Source Geospatial Foundation Project, 2020. Disponível em: http://qgis.org. Acesso em: 04 set. 2021.

R CORE TEAM. R: A language and environment for statistical computing. R Foundation for Statistical Computing, Vienna, Austria, 2019. Disponível em: https://www.R-project.org/. Acesso em: 04 set. 2020.

RIVERO, M. S. Análisis espacial de datos y turismo: nuevas técnicas para el análisis turístico, una aplicación al caso Extremeño. Revista de estudios empresariales. n. 2, p.48-66, 2008. Disponível em: https://revistaselectronicas.ujaen.es/index.php/RE E/article/view/365. Acesso em: 13 set. 2021.

SILVA, A. de B. Análise quantitativa espacial: conceitos e fundamentos. $1^{\mathrm{a}} \mathrm{ed}$. Curitiba: Appris, 2018. 325p

SILVA, R. C. da; FONSECA, M. A. P. da; BORGES, A. L. M. Turismo e gestão de investimentos públicos: uma análise nas regiões turísticas do Rio Grande do Norte - Brasil 2003/2016. Tur. Visão e Ação, Santa Catarina, v. 23, n. 1, p.26-47, jan/abr, 2021. http://dx.doi.org/10.14210/rtva.v23n1.p26-47.

SOUZA, P. I. A. de; SILVEIRA NETO, R. DA M. Identificação e caracterização de clusters potenciais de turismo no Nordeste: uma análise exploratória a partir de dados da PNAD. Revista Brasileira de Estudos Regionais e Urbanos, v. 2, n. 1, fev. 2015. Disponível

https://www.revistaaber.org.br/rberu/article/view/4 0/70. Acesso em: 06 set. 2021.

TRIPADVISOR. TripAdvisor: leia avaliações, compare os preços e reserve. c2021. Disponível em: https://www.tripadvisor.com.br/. Acesso em: 13 set. 2021.

\section{CONTRIBUIÇÃO DOS AUTORES}

Erickson Melo de Albuquerque orientou a metodologia adotada, idealizando a exploração das técnicas e ferramentas de análise geoespacial, como também colaborou na escrita e revisão do texto. Eduardo Rodrigues Viana de Lima analisou e selecionou as técnicas e ferramentas adequadas ao estudo, adquiriu os dados utilizados e iniciou a redação do texto. 